\title{
An exploration of Accounting Teaching
}

\author{
ShenHongyi \\ Tibet University for Nationalities \\ Shanxi Xian yang, China \\ Shenhy688@126.com
}

\begin{abstract}
Aiming at the" theory and practice" of accounting teaching mode, this thesis deals with how to strengthen financial supervision as an example, explored from" problem, problem analysis, and then to solve the problem of" a new teaching idea, embodies the "practice - Theory - practice" teaching method in the real connotation and practical significance of accounting, to the whole teaching work has a positive role in promoting.
\end{abstract}

Keywords-component; accounting teaching; exploration

\section{INTRODUCTION}

Refer to accounting teaching mode, mostly from "theory And practice" of a kind of train of thought, namely the first rational knowledge, and then to the perceptual knowledge. In the classroom the teacher always taught various basic theory and methods, to guide students to practice should permit and apply these principles and methods, which often leads to the students of knowledge understanding is insufficient, understanding is not enough, not strong interest in practice many problems and disadvantages. Here, we might as well be this kind of teaching mode " industry chain " to extend forward, which makes the students to master knowledge and content have a preliminary understanding ( practice ), and then on the basis of perceptual knowledge of phenomena and problems are concluded and analyzed, in order to enhance the rational knowledge, and then systematic learning of theoretical knowledge ( Theory ), and then returning to practice should permit and applying these theories and methods ( practice), to help them enhance coping and solve various practical problems, followed by a "practice Theory - practice " teaching thought.

\section{PROBLEM PUT FORWARD ( PRACTICE )}

For what is finance students and completely understand, because previously not true contact and engaged in such work,

About how to establish and improve fiscal funds regulatory pathways and the system is not clear. Here, we do not have direct access to about financial supervision of the various approaches and methods, and should be in the teacher's guide and drive down inspired students to design problems (i.e. questions), i.e. what is the financial supervision? Can make use of the reality of what is happening all the phenomenon of violation of discipline and corruption behavior of real cases and data, to help students to strengthen financial supervision work background and environment have a clear understanding and understanding, then by virtue of their own some personal view heard and knowledge of space imagination, puts forward some on the financial capital in the management and use it exist some loopholes and problems, then organize students to these loopholes and problems by induction and summary of the analysis, in order to teach how to take effective measures to control and prevent laid the foundation. The teaching effect is often compared to the classroom only to teachers teaching an effect is apparent, but also can fully arouse students' interest and participation.

First of all, through some real case, inspire and guide students to understand finance capital in the management and use of the process will have various drawbacks and problems; here we can be expressed as capital project is not real, or was

changed the use and nature, to superintend the job does not reach the designated position, overall efficiency play does not come out, Bacon an rise to basically have seven aspects: one is a department or unit leaders for the funds lack of awareness of the importance of. On the thought did not cause enough attention, don't really have the funds in accordance with the provisions of the requirements into separate accounts, and is often associated with the various public utilities expenses become confused, adverse economic business reflect and accounting, which also affected the normal economic supervision and auditing work; two is the interception, occupy the phenomenon is relatively common, misappropriation. Some departments and units are always managed to intercept, purposes, various types of special funds allocated by the above, incorporate is in: (1) authorities intercepted in transit or occupy subordinate units of special funds; (2) the project implementation unit of cash or transfer funds, even with the implementation of the project expenses unrelated to other cost accounting; three subjects confusion, billing record is not perfect. Performance in some units will be special funds allocated and used not in accordance with the provisions of the accounting treatment procedures in the relevant accounting subjects, but rack one's brains for ingenious devices or another account, cannot really reflect the part of the essence of the economic affairs; four is a special fund mutual use, borrow the phenomenon is very common, is not up to the true meaning the " special fund is special ". Mainly in some project implementation units in the overall use of funds on 
the east down West, as long as you have the money, leading some to real project funds according to the provisions of the use, thus changing the original funds and properties, and also influences the efficiency and effectiveness of play; five is illegal expenditure it occurs. The main form of administration expenditure, economic procedure is not legitimate, "steal, cheat, escape, evasion” rampant; six is a project is completed, check and acceptance work lag. Some units project is completed after a long time, always for this and other reasons, the inspection work late and not timely, or although already undertook checking and accept, but the project quality control and auditing supervision to flow at the form, make the project reach the expected purpose. Even the project unfinished had early aborted, become waste mound a, to the nation and the people have caused property losses and waste of funds, social echo is extremely bad; seven is the financial regulatory supervision strength is not strong, the law enforcement inspection work in place. As a special financial regulators, discipline inspection, auditing, finance, hair change appoint wait for a branch and relevant project manager is often in project review check strictly, funds for the catch closely, and in the implementation of the project has put loosely, cause capital and project supervision work does not reach the designated position, or at least some cross period big, long interval of post audit or middle smoke careful, do not play the real meaning of " tracing efficiency ". Through to these problems were summed up, can make the students learn to basically in fiscal funds management and use

Of the process really exist problems and malpractice that strengthens financial supervision work is very important. Then, combined with the financial capital of the meaning and content of detailed, comprehensive ground is elaborated, can strengthen the students' understanding and points of interest. The finance is national finance as the center, not only including the central government and the local government's financial revenue, is also included with the national finance related enterprises, institutions and the administrative units of the monetary payments, it is a national social capital dominant, to social capital operation has great control and influence. The main body is the source of tax revenue and state-owned enterprises turn over part of the profit after tax. On the financial management and use of funds, not only do the norms of science, uses clear, but midway may withhold, occupied or misappropriated funds, must reflect the timeliness and effectiveness. In addition to the tax is mandatory, in reality taxing job is not an easy thing, the increasingly fierce competition in the market economy environment also makes greatly small enterprise profit space getting smaller, resulting in a national tax resource is very limited and defense, basic construction, disaster relief and other expenses, increasing trend year by year, the financial resources has a " scarcity " and asked to play the maximum benefit " ". Thus, for all types of financial malfeasance case, every year the government will cost very great strength to undertake investigating, although various government and branch of the capital in the management and use of strict examination review, also frequently, but check repeatedly made, not eradicate. What are the causes and induce various law cases and to check repeatedly more than? In this, it is necessary for us to further discussion and analysis of the problems and root causes. So, make students easily from the initial perceptual knowledge to rational analysis phase.

\section{PROBlEM ANALYSIS ( THEORY )}

Help the students to find and put forward problems, had to Guide and inspire them to further on the existing phenomenon

And problem analysis and summary, promotion from perceptual knowledge to rational knowledge stage phase transformation, in order to cultivate and enhance their ability of analyzing and solving problems, this is our teaching goal. In the example above we have talked about how to guide the students to analyze and summarize the financial illegal phenomenon and problem, but now to help them carry on analysis and discussion of these phenomena and problems causes and origins. In the analysis the root of the problem, must first help them learn how to analyze problems, namely the establishment of an analysis of the basic idea and method, such as for the financial supervision, we must first clear cause and trigger these issues the factor to have? In reality, the factors which affect it may be many, but Bacon and rise nothing more than two categories, namely, the internal and external factors, or further may be further subdivided into system, mechanism and human aspects and so on. Here, we can and will affect financial regulatory factor analyses briefly summarized in the following points:

- Some departments and units leading legal idea is thin, the financial laws and regulations knowledge through learning and less publicized. They often do not pay attention to strengthen the policy laws and regulations and professional knowledge of the study and conduct propaganda, in the management and use of the Department, the unit financial funds free, easy to breed such as corruption and cause various violations occur

- Part of the business personnel responsibility is not strong, the established rules enforcement. In part of the project person in charge and business managers, cannot fulfill their duties, the established rules and regulations in the implementation process easy go out of form, units of the internal control system is lax, there should be no constraint and restrict action.

- Individual inspection of law enforcement officials to investigate the work not thoroughly, to violate the law and discipline behavior cannot produce a deterrent effect. Mainly is some law enforcement personnel hinder at feelings and crooked where affection to violate the law and discipline, investigate and punish the acts as a mere formality, 
not necessarily control and regulatory roles in society, simply cannot produce a strong deterrent effect.

- The existing financial supervision system is not perfect, for the administration of special funds and the use of standard function is not strong. Due to time, manpower, material resources, financial resources and other conditions and factors of the restriction, not every transaction happens will have various regulatory authorities to effectively carry on the "tracing efficiency ". At present, special fund in management and use of the process standard function is not very strong, scientific and reasonable supervision and restriction mechanism is still in continuous exploration and improvement, have not formed a set of so-called can reach to advance, in the matter, after the control of all walks of life and all appropriate com. Universal, effective and unified funds supervision and control system.

To this problem is to find the analysis of the real reasons And causes, this also is a ceaseless exploration and thinking process, in this process the key is to guide students to analyze and to seize the masterstroke of the problem and focus, and then sort out the problem of main contradiction and contradictory main field, for the further respond and solve these problems to lay the foundation. Below we will talk about how to guide the students to respond to and solve these problems.

\section{PROBLEM SOLVING ( PRACTICE )}

The above mentioned that students can use to learn and master the knowledge and theory to deal with and solve practical problems is our teaching goal. Then, in the reality of accounting teaching us how to cultivate students' the ability? The answer is from " theory " to return to the "practice " in go, is through the classroom has taught various knowledge and business skills were carefully reviewed and summarized, including accounting, auditing, finance, taxation, law and other related fields and the scope of business, to guide and help students to translate theory, system the application of knowledge to practical work. This is not just a simple course operation, but involves many courses and professional comprehensive knowledge fusion and penetration, is a real sense of complete from the "theory " to" practice " phase of the transformation, the only way to achieve the "live" and " integrating theory with practice ". Now, back to our teaching case, how to manage and use the good financial capital? Here, you can consciously guide the students to learn the " accounting system design ", " financial management ", " accounting ", " non profit organization accounting ", " audit " and " economic law " and other related courses and some financial laws and regulations and financial regulations, to help students to finish the work. The following is how to strengthen financial supervision suggestions and measures, for reference only.
- Strengthening the system of job responsibility investigation system, execute assessment: first of all, departments, units of the leading cadres should go up from the thought to give height takes seriously, strengthen the system of job responsibility, fully aware of the importance of national finance special funds; secondly, the departments and units responsible person and the project management personnel to establish the strict examination system of prosecution, so that they are able to comply with the national financial laws and regulations and financial regulations, effective management and use their own hands ", this part of the limited funds " protection of all kinds of financial fund standardized operation and reasonable use, avoid interception, occupy, divert phenomenon.

- Increase superintendence job strength, improve work efficiency, and discipline: audit, finance, policy, capital supervision departments must increase both inside and outside the capital to superintend strength, especially to strengthen the audit ( AUDIT) working group of the supervision and management of special funds, the supervision and inspection work on important schedule. Through the establishment of multiple levels, all-around, wide field supervision and inspection system to continue to strengthen the capital to superintend strength and improve efficiency in the use of funds, and as a long-term, persistent and strategically the job will catch.

- Improve the internal control system; ensure the safety of funds and legal. Each project carries out a unit to should perfect internal control procedures, to strengthen internal control and supervision, to further standardize the project funds financial management system and method. On the special fund management and use should be clear responsibilities, division of responsibilities, rights, improve the examination and approval, implement standard of special accounts management and democratic supervision, to effectively guarantee all kinds of financial capital is reasonable use and safety legality.

- The establishment of practical funds "performance tracing system ". From the practice in daily work constantly sum up and accumulate experience, from their respective nature of the industry and business characteristics, do so from the fine audit, strictly guard the pass, as much as possible for each amount of special funds from the examination and approval, appropriate to use each link can be " tracing efficiency ", and put an end to the waste of funds and project false phenomenon, and resolutely from the source to contain and eliminate all kinds of violation of discipline and behavior problems. At the same time, should also increase the financial laws and regulations and financial management of content knowledge learning and propaganda work, 
strengthen personnel training and business skills to improve, so it can more reasonably and scientifically to implement projects and economic supervision, financial supervision and control of funds to build a good atmosphere and environment.

\section{CONCLUSION}

So, to a certain extent, can effectively promote the financial

Manage. Through the discussion and analysis of financial supervision which is a teaching case, help us to look from a " problem, problem analysis, and then to solve the problem of the real meaning of "teaching methods, completed the "practice - Theory - practice" new accounting teaching exploration. Accounting is a course with strong practicality, and its related disciplines integrated fusion and correlation degree is very high, the new teaching ideas and methods of exploration, not only can enhance the students' comprehensive ability to analyze and solve problems, and to promote the whole accounting teaching has a positive role.

\section{REFERENCES}

[1] Wang Xiuzhi. The National People's Congress on the government budget supervision of the five [J]. big problem of financial supervision, 2009 ( 7).

[2] Shen Hongyi. special fiscal funds regulatory [J]. development, 2006(7)

[3] Chi Lingna. Discussion about accounting occupation education reform [J]. cooperative economy and science and technology, 2008(1)

[4] Guo Yanlong. Analysis on Chinese accounting education reform problems in the $[\mathrm{J}]$. finance and accounting monthly, 2005 ( 15)

[5] Jiang Shouwen. Discussion on Cultivation of Applied Talents in local colleges and universities [J]. Journal of Taiyuan City Vocational College, 2010(9). 